\title{
Organização espaço temporal do rolamento para frente
}

Alaercio Perotti Júnior* e Ana Maria Pellegrini*

\section{Resumo}

Este estudo focaliza a execução do rolamento para a frente levando em consideração as restrições ambientais (tatame e colchão) e internas impostas pelo crescimento e desenvolvimento. Retratos de fase dos segmentos corporais, obtidos a partir da posição e velocidade angulares, foram analisados. As trajetórias das órbitas dos segmentos perna, coxa e tronco demonstraram ser diferentes entre si e semelhantes entre os sujeitos, independentemente da idade cronológica (5-6, 8-9, 11-12 anos e adultos) e superfície de apoio (colchão e tatame). Menor variabilidade nos retratos de fase dos segmentos corporais foi observada em adultos quando comparada com as das demais faixas etárias.

UNITERMOS: Desenvolvimento motor, rolamento para frente, atratores, retratos de fase, organização espaco-temporal

\section{Abstract}

This study focus on the forward roll taking into account the environmental constraints due the surface (mattress and tatame) and intrinsic constraints imposed by growth and development. Phase portraits of body segments obtained from angular displacement and velocity were employed for ihe analysis ofthe spatial-temporal organization of the performance. The trajectories ofthe orbits of of the leg and trunk segments showed to be different among themselves but similar between subjects, mdependently of chronological age and surface used. Less variability in phase portraits of body segments was observed in adults as compared with the younger age groups.

Key words: Motor development, forward roll, atirador, phase portrait, spatio-temporal organization

\section{Introdução}

No contexto da área de estudo do desenvolvimento motor, entender como se dá o processo de mudanças na coordenação e controle motor ao longo do tempo é uma preocupação permanente entre os investigadores. A Abordagem dos Sistemas Dinâmicos (ASD) postula que novas formas emergem da $O$ movimento cooperação e interação de
múltiplos componentes angular do corpo dentro do contexto da no rolamento é tarefa. Assim, a coorde-conseguido pela nação e o controle do coordenação dos tronco e membros para a membros, cabeça e execução de uma habilidade são extensões resultados de um harmoniosas
relacionamento de forças musculares e não-musculares, incluindo o ambiente, a atividade do organismo e as forças reativas que emergem da interação entre o organismo, o ambiente e a tarefa.

O interesse, neste estudo, pelo rolamento para frente, habilidade conhecida como cambalhota, se justifica porque, embora esta habilidade possa ser considerada complexa, exigindo um grande 
relacionamento de forças, crianças muito jovens a realizam. No entanto, a performance desta habilidade muda ao longo dos anos. A criança consegue coordenar e controlar o sistema efetor, obtendo grande eficácia na realização desta ação motora. É uma habilidade bastante diversa das demais habilidades que compõem o repertório motor das crianças. Esta habilidade tem sido raramente investigada, principalmente a partir da década de 80 , com a aplicação de pressupostos da ASD no estudo do desenvolvimento motor. Segundo THELEN e ULRICH (1991), esta abordagem parte do pressuposto que novas formas de comportamento emergem da cooperação e interação de múltiplos componentes dentro do contexto da tarefa. Esta abordagem está apoiada em transições não-lineares, onde um modelo preferido de comportamento é substituído por uma

Quando o executante
aplica força a uma
superficie estável,
uma força contrária
volta ao corpo,
sendo que quanto
menos estável for a
superficie, menor será
esta força contrária
nova forma. Este paradigma, bastante rico, permite endereçar questões de desenvolvimento de coordenação e controle das ações motoras, oferecendo subsídios que permitam compreender as mudanças que ocorrem na execução do rolamento para frente.

Na execução do rolamento, o corpo realiza uma volta completa em contato com uma superfície de suporte e, portanto, o deslocamento do corpo ocorre no plano sagital, em volta do eixo lateral. A forma mínima requerida para um giro completo para a frente é de cento e oitenta graus sobre a cabeça, caindo sobre as costas (WICKSTROM, 1983). Segundo HAYWOOD (1986), para que um rolamento para frente seja considerado completo, o indivíduo deve se mover junto do solo, iniciando e terminando sobre os pés. O peso do corpo deve sucessivamente se apoiar no solo, iniciando pela parte posterior da cabeça. Em seguida, as partes superior e inferior das costas e por fim os quadris.

Embora seja um padrão motor que crianças mesmo muito jovens consigam realizar logo nas suas primeiras tentativas, ele é executado por elas de forma descoordenada, com a presença de muitos movimentos desnecessários. Ao longo do desenvolvimento, a criança adquire controle sobre alguns aspectos do rolamento, como a manutenção do alinhamento do corpo, velocidade e economia de movimento, aperfeiçoando de forma progressiva esta habilidade. O movimento angular do corpo no rolamento é conseguido pela coordenação dos membros, cabeça e tronco, em flexões e extensões harmoniosas. Todas as ações são cumulativas de modo que uma falha em uma das ações (como uma falha de sustentação do corpo nos braços) influencia o movimento como um todo. Para NEWELL (1985), as propriedades topológicas do movimento, relativas ao tronco e membros, especificam uma dada atividade. No caso do rolamento para frente, o deslocamento da cabeça, tronco e membros em relação ao solo, num giro de $360^{\circ}$, caracteriza esta habilidade.

Quando o executante aplica força a uma superfície estável, uma força contrária volta ao corpo, sendo que quanto menos estável for a superfície, menor será esta força contrária. Se a superfície possuir muita acomodação ou ceder bastante, a força contrária é dissipada, limitando portanto a magnitude da força que pode ser repassada ao executante, e o resultado final é uma menor propulsão. Assim, no presente estudo, as duas superfícies de apoio foram selecionadas de modo a exigir ajustamentos, por parte do executante, específicos às características de tensão da superfície de apoio.

Diferenças consideráveis na performance de habilidades motoras podem ser percebidas intra e entre indivíduos, parecendo impossível a um dado indivíduo gerar padrões idênticos de movimento em sucessivas tentativas de execução de uma mesma tarefa. Segundo KELSO, DING e SCHÖNER (1993), a estabilidade (habilidade 
em persistir sob várias condições ambientais) e a flexibilidade (habilidade para ajustar-se a mudança nas condições internas ou externas) devem ser características fundamentais de quaisquer princípios de organização. A estabilidade, para KELSO e DING (1993), desempenha um papel central, mais dramaticamente evidente quando a mesma é perdida. Esta perda leva a mudanças na coordenação. No presente estudo, as alterações na superfície de apoio não seriam suficiente para mudanças no padrão de coordenação do rolamento, mas a flexibilidade permitiria os ajustamentos necessários e são estes ajustamentos frente a restrição externa que serão focalizados no presente estudo.

Há evidências não apenas de que padrões observados correspondem a estados atratores mas também que a mudança de um a outro atrator é devida à perda de estabilidade do sistema (KELSO, DING \& SHÕNER, 1993). O atrator indica apenas a preferência do sistema para determinados estados, aparecendo quando o sistema se encontra em equilíbrio, auxiliando em sua manutenção (THELEN \& ULRICH, 1991).

O sistema prefere uma certa topologia em seu estado de espaço ou plano de fase. O traçado topográfico de um sistema dinâmico consiste no mapeamento do comportamento de uma variável coletiva, ao longo do tempo, em um estado ce espaço apropriado que capte a compressão dos graus de liberdade. $\mathrm{O}$ estado de espaço é limitado por variáveis do sistema e ilustra qualitativamente as posições onde o sistema reside e onde as trajetórias são atraídas.

A representação gráfica do sistema, segundo CLARK, TRULLY e PHILLIPS (1993), é chamada de plano de fase ou retrato de fase, e é obtida a partir da posição e da velocidade angulares de um segmento na realização de um movimento. Conforme CATUZZO (1994), o uso do retrato de fase é um modo alternativo de se descrever um padrão de coordenação ao longo do tempo. As características topológicas da cinemática, emergem indepen- dentemente da atividade ser cíclica ou não. Mudanças na estrutura topológica da cinemática do movimento também poderão ocorrer na performance motora de adultos conforme as exigências da tarefa. Assim, uma análise topológica do desenvolvimento de padrões de movimento oferece uma base mais segura para detectar mudanças qualitativas nos padrões de movimento da criança em desenvolvimento. (NEWELL, 1985). Através da posição e $\mathrm{Na}$ tentativa de res- velocidade angulares ponder a algumas das na realização do muitas questões exis- rolamento para frente tentes, este estudo foi possivel analisar pretende analisar o as trajetórias dos padrão do rolamento segmentos perna, coxa para frente diante das e tronco

restrições internas e externas, ou seja, verificar a organização espaço-temporal do rolamento para frente perante restrições internas impostas pelo crescimento e desenvolvimento, peculiar a diferentes faixas etárias, e restrições externas impostas por situações ambientais diferentes. Mais especificamente verificar:

a) quais são os ajustamentos na organização espaço-temporal dos segmentos da perna, coxa e tronco em diferentes faixas etárias, frente a variações nas restrições orgânicas, estruturais e funcionais (internas) na execução do rolamento para frente;

b) quais os ajustamentos na organização espaçotemporal dos segmentos da perna, coxa e tronco frente às restrições impostas por superfícies diferentes (colchão e tatame).

\section{Método}

Sujeitos: Participaram deste estudo, 4 crianças em cada uma das faixas etárias de 5-6, 8-9, 1112 e quatro adultos. Os participantes atende- 
ram voluntariamente divulgação sobre o projeto, não havendo preferência quanto ao sexo por não haver indicativo, na literatura, quanto à diferença entre os sexos na execução desta habilidade. Participaram deste estudo apenas crianças e adultos sem treinamento específico anterior nesta habilidade, comum na prática do judô e da ginástica artística.

Procedimentos: Cada um dos participantes

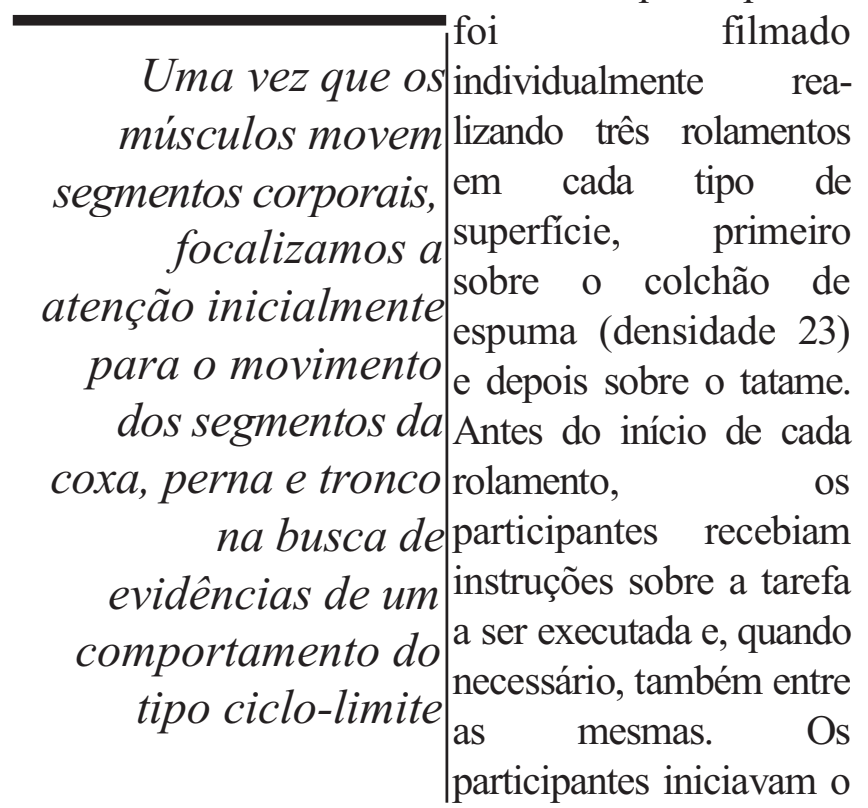

rolamento, posicionando-se atrás de uma marca, previamente colocada nos pisos, iniciavam o rolamento a partir de uma posição ereta, não sendo permitido andar ou correr para aumentar o impulso inicial na execução do rolamento.

A filmagem foi realizada no ginásio de ginástica artística e, para aumentar o contraste figura-fundo no registro visual, foi colocado um fundo verde em uma das paredes, próximo ao local no qual foram realizadas os rolamentos. Os participantes tiveram as articulações do tornozelo, joelho, quadril, ombro, do lado direito, marcadas com um círculo branco, de aproximadamente $2.5 \mathrm{~cm}$ de diâmetro, circundado em preto, para melhor contraste. Os participantes estavam vestidos com sunga ou maio de modo que as marcas nas articulações estivessem bem visíveis.
A câmara foi posicionada perpendicularmente à região central de uma área demarcada para a performance motora, a uma distância de $4 \mathrm{~m}$ e altura de $1 \mathrm{~m}$ do solo. Todos os participantes foram filmados do lado direito. No início de cada uma das sessões de filmagem das performances motoras dos participantes, uma cruz era filmada para fins de obtenção de referencial da escala métrica. $\mathrm{O}$ intervalo de tempo entre os registros era de $0,033 \mathrm{seg}$.

Decodificação e tratamento dos dados: Dos três rolamentos executados, um deles foi selecionado para análise, com base nos seguintes critérios: a) que todos os pontos articulares estivessem visíveis; b) pouca ou nenhuma rotação do corpo, durante o rolamento, para não prejudicar a visualização das partes do corpo, c) que os participantes estivessem em pé, parado para o início do rolamento, não sendo permitido qualquer tipo de corrida preparatória.

As imagens dos rolamentos selecionados foram transferidas para o micro computador e capturadas via VIDcap. Em cada um dos quadros, os pontos demarcados foram digitalizados (coordenadas $\mathrm{x}$ e y) na seguinte ordem: tornozelo, joelho, quadril, ombro. De posse das coordenadas "x" e "y", foram feitos os gráficos, unindo os pontos articulares através do programa Wgraphil. Na Figura 1, um círculo foi adicionado ao final do segmento dotronco para ilustrar a cabeça do participante, permitindo uma inspeção visual inicial dos desempenhos de todos os participantes.

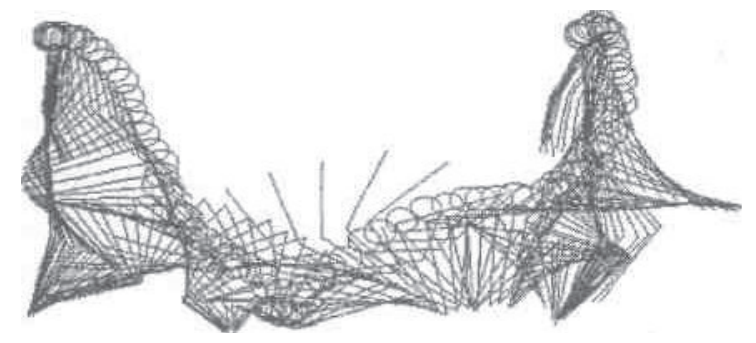

Figura 1. Representação gráfica do rolamento para frente via Wgraphil a partir das coordenadas $x$ e $y$. 
Após a captura das coordenadas bidimensionais "x" e "y", de cada ponto articular, os dados foram filtrados \{Fast Fourier Transformation - FFT). Em seguida foram calculados os ângulos de cada um dos segmentos corporais perna, coxa e tronco, em relação ao eixo horizontal (Figura 2) e obtidos o deslocamento e a velocidade angular de cada segmento corporal.

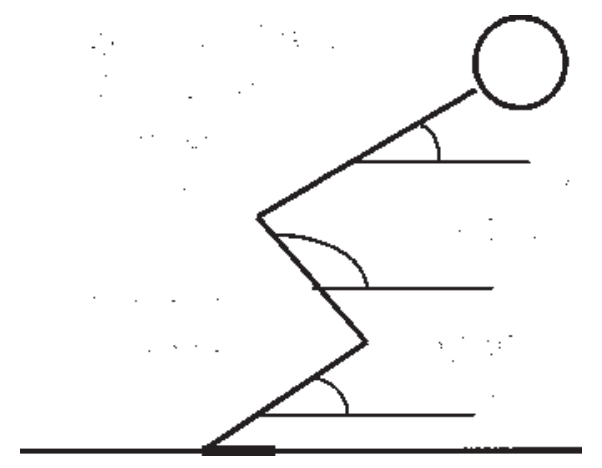

Figura 2. Representação gráfica dos segmentos (tronco, coxa e perna) em relação ao solo.

Com base nestes dados foram plotados os retratos de fases. $\mathrm{O}$ valor da posição angular foi projetado no eixo "X" (abcissa) e a respectiva velocidade angular no eixo "Y" (ordenada), como pode ser visto na Figura 3.

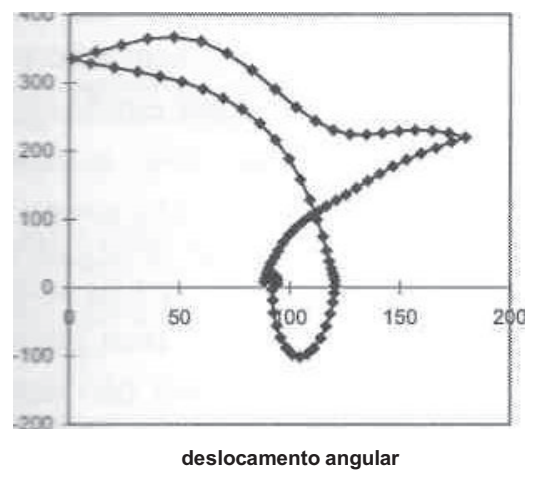

Figura 3. Retrato de fase referente ao segmento coxa na execução do rolamento para frente sobre o colchão (Ss 16).
Os gráficos dos retratos de fases foram normalizados, de modo que, o maior valor do deslocamento angular e velocidade angular no retrato de fase de um determinado segmento foi considerado 1 e o menor valor -1 (Figura 4). Este procedimento permitiu a comparação entre retratos de fase de segmentos diferentes.

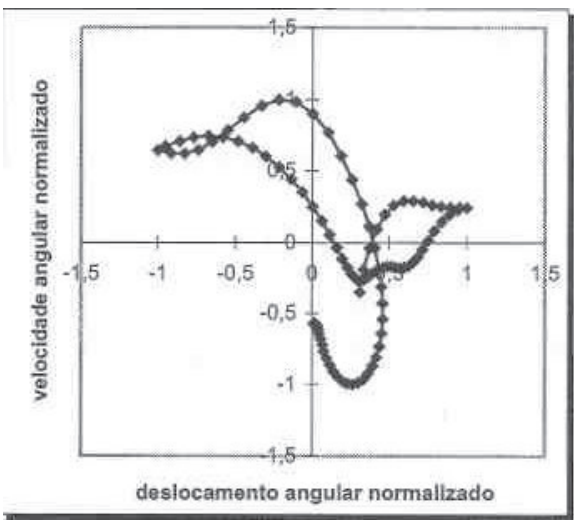

Figura 4. Retrato de fase normalizado do segmento coxa na execução do rolamento para frente sobre o colchão (Ss 16).

De posse dos gráficos e dados das posições No início, o segmento angulares dosperna apresenta um membros, três prin-фleslocamento cipais reversões foram pequeno para em identificadas para os \$eguida realizar uma segmentos perna, coxa trajetória bastante e tronco. Uma mudança evidenciada para fora vimento de um seg- la região central da mento em relação ao órbita, indicando solo é considerada uma introdução de reversão. Um exemplo energia, de reversões pode ser correspondente ao visualizado no gráfico do deslocamento qumento da posição e angular da coxa (Figura yelocidade angulares $5)$. 


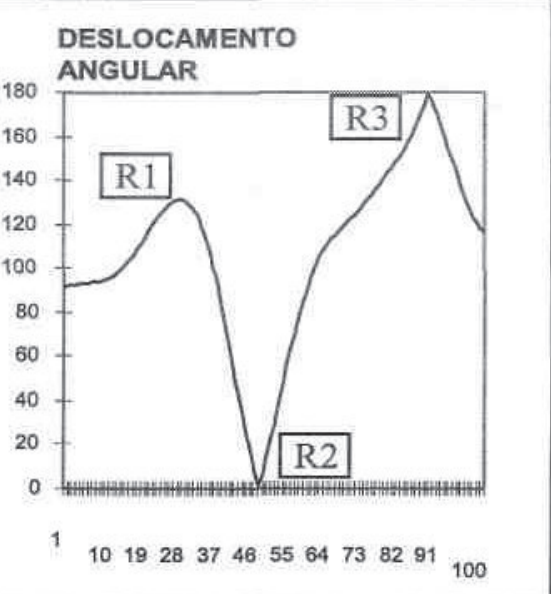

Figura 5. Reversões (RI, R2, R3) do deslocamento angular da coxa na execução do rolamento para frente sobre o colchão (Ss 16).

\section{Resultados}

Através da posição e velocidade angulares na realização do rolamento para frente foi possível analisar as trajetórias dos segmentos per na, coxa e tronco. Na Figura 6 são apresentados

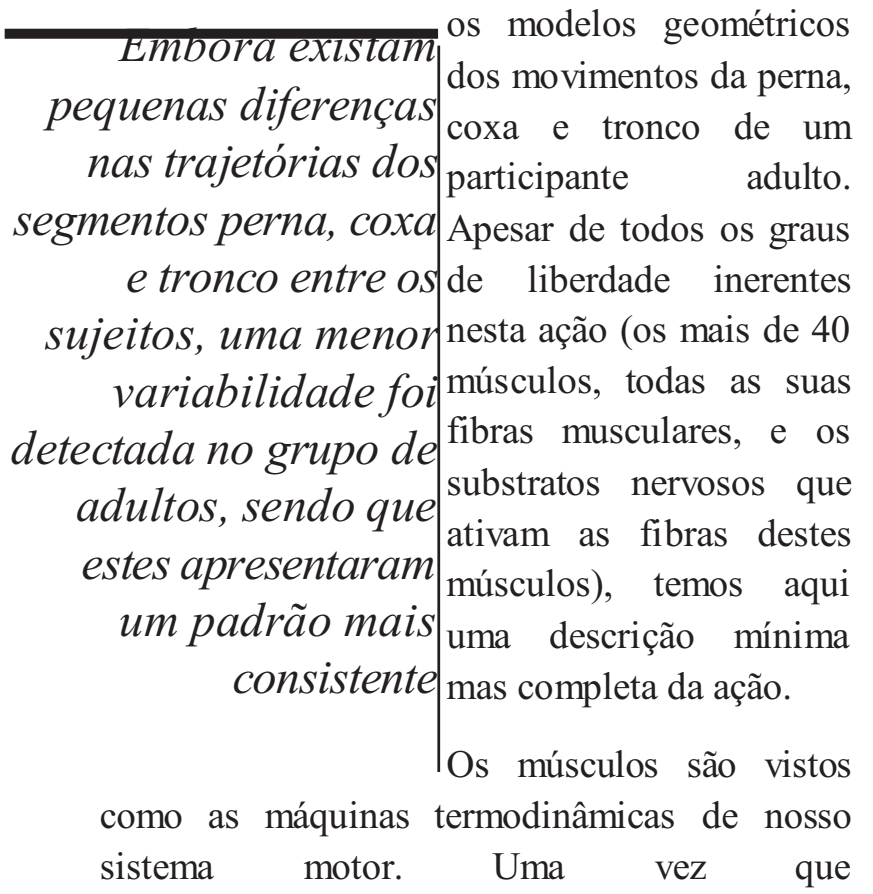

os músculos movem segmentos corporais, focalizamos a atenção inicialmente para o movimento dos segmentos da coxa, perna e tronco na busca de evidências de um comportamento do tipo ciclo-limite. Segundo CLARK, TRULLY e PHILLIPS (1993), um ciclo-limite é um atrator que não descansa, mas circula periodicamente numa órbita fechada de modo que o praticante executa o movimento repetidamente. O rolamento pode ser executado várias vezes, em seqüência de tal forma que executante não retorne à posição inicial (de pé) entre rolamentos. Embora, no presente estudo, os participantes tenham executado apenas uma performance, fica evidente que ela se comporta como ciclo-limite. O comportamento observado não se repetia, mas acreditamos que o rolamento, em si, siga os mesmos princípios de um ciclo-limite. Ele também retorna à mesma região do estado de espaço (a trajetória do atrator), se ligeiramente perturbado ou com início em modos (ou estados) diferentes.

Embora sejam de um mesmo ciclo completo do rolamento, os três segmentos corporais exibem comportamentos periódicos cujas órbitas, nos planos de fase, são fechadas e atraídas a regiões particulares do estado de espaço e, se perturbadas (tal quando elas iniciam) ou se as condições de inércia forem alteradas, elas retornam rapidamente à órbita original. Segundo CLARK, TRULLY e PHILLIPS (1993), esta propriedade dos ciclos-limites se refere a sua estabilidade estrutural. Portanto, como esperado, todos os segmentos corporais dos participantes analisados neste estudo apresentaram estabilidade estrutural.

As trajetórias dos segmentos perna, coxa e tronco eram qualitativamente diferentes mas semelhantes para todos os participantes, com pequenas variações. Os resultados indicam não haver diferença na organização espaço-temporal destes três segmentos entre as diferentes faixas etárias e, portanto frente às restrições internas.

Especificamente, o retrato de fase da perna do participante 3, na execução do rolamento no 


\section{-}
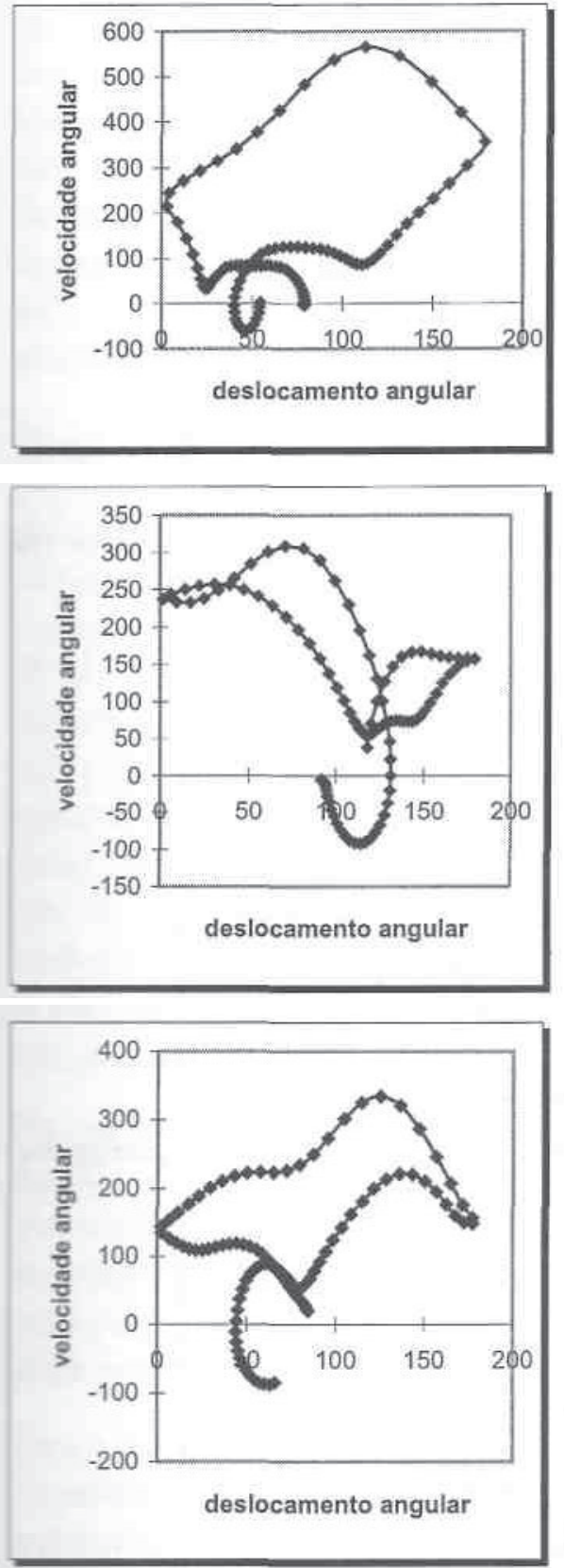

Figura 6. Orbitas atrativas dos segmentos da perna (A), coxa (B) e tronco (C), na execução do rolamento para frente sobre o colchão (Ss 13).

tatame apresentou variação no deslocamento e velocidade angular, evidenciando um aumento dos mesmos, embora a trajetória deste segmento seja semelhante a dos demais participantes. Revendo a performance deste participante, foi constatado que ele utiliza apenas uma perna para o impulso, jogando o corpo de forma brusca e não controlada, exibindo, na fase do rolamento propriamente dito, um estágio menos avançado do que os demais participantes de seu grupo, demonstrando provavelmente nível inferior de controle.

Conforme CLARK, TRULLY e PHILLIPS (1993), a perna como uma porção distai do membro inferior tem amplitude e velocidade de movimento maiores do que a coxa, que é uma porção proximal do membro inferior. $\mathrm{O}$ raio da trajetória é uma medida do trabalho necessário para manter a mesma, e flutuações para dentro, representariam a perda de energia, enquanto flutuações para fora representariam uma injeção de energia. Presumivelmente, quanto maior a flutuação na trajetória de um segmento, maior a dissipação de energia.

A trajetória do segmento perna inicia o deslocamento em torno de $80^{\circ}$ e vai diminuindo até próximo de $0^{\circ}$, onde se dá a primeira reversão. A partir daí, o deslocamento angular da perna começa a aumentar devido a maior velocidade angular, na fase de rolamento propriamente dito, ou seja, quando os pés perdem o contato com o solo, até novamente tocá-lo para iniciar a elevação do corpo. Quando o segmento da perna se aproxima de $180^{\circ}$ e inicia a segunda reversão, a velocidade angular vai diminuindo gradativamente até a perna se aproximar de $50^{\circ}$. Ou seja, quando o indivíduo começa a se levantar, ele eleva o segmento da coxa além dos $90^{\circ}$ provocando uma nova reversão, e o segmento perna começa a estender-se ficando próximo de $70^{\circ}$ ao final do rolamento. No início, o segmento perna apresenta um deslocamento pequeno para em seguida realizar uma trajetória bastante evidenciada para fora da região central da órbita, indicando introdução de energia, correspondente ao aumento da posição e velocidade angulares (BARELA, 1992).

O segmento coxa atua de uma forma contrária ao da perna, como citado anteriormente. Este 
segmento inicia a impulsão por volta de $130^{\circ}$, atingindo também sua maior velocidade angular durante o rolamento propriamente dito até se aproximar de $0^{\circ}$. Neste momento, o segmento coxa fica paralelo ao plano horizontal, quando há, então, uma nova reversão e seu deslocamento angular começa a aumentar até aproximadamente $90^{\circ}$ ao término do rolamento. No início do deslocamento, o segmento da coxa apresenta, assim como o da perna, mudanças marcantes nos níveis de energia durante o seu ciclo, embora a perna pareça ser um sistema mais conservador do que a coxa, evidenciando poucas flutuações para dentro ou para fora de sua órbita.

Os quatro grupos etários apresentaram, para o segmento tronco, um padrão topológico semelhante, com o início do deslocamento em torno de $90^{\circ}$, diminuindo até se aproximar de $0^{\circ}$, quando ocorre a primeira reversão e a ação de rolar propriamente dita. A impulsão dada pela coxa provoca a extensão do quadril que, por sua vez, faz com que o deslocamento angular do segmento tronco comece a aumentar chegando próximo aos $180^{\circ}$. Isto faz com que este segmento fique paralelo ao solo, e em seguida ocorra uma nova reversão e o tronco comece a se elevar diminuindo o deslocamento angular ultrapassando o eixo de $90^{\circ}$ terminando por volta de $50^{\circ}$. Neste ponto se dá a última reversão e o aumento do deslocamento angular termina por volta de $80^{\circ}$, ou seja, com a extensão do tronco ao final do rolamento.

A fase de propulsão do rolamento é muito importante uma vez que ela é responsável pela elevação do corpo e retomada da posição "em pé". O membro inferior, identificado como perna, é composto de três segmentos (coxa, perna e pé) que se articulam no quadril, joelho e tornozelo. Os retratos de fase mostram as diferenças biomecânicas entre os segmentos da perna, coxa e tronco. Na preparação da impulsão do movimento, o segmento coxa realiza movimento em sentido contrário ao dos segmentos perna e tron-

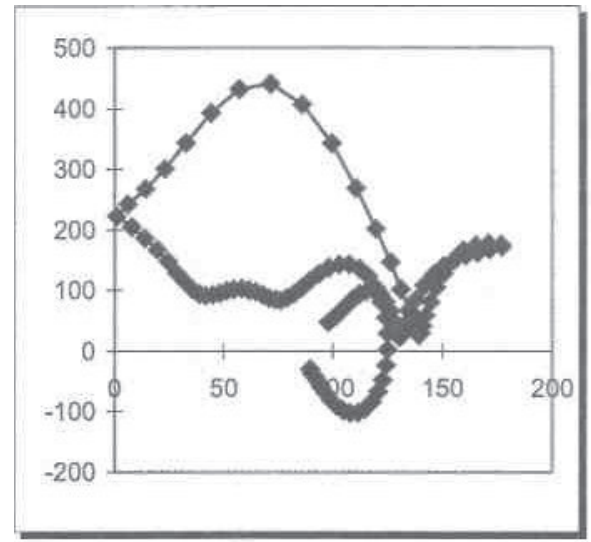

A) Retrato de fase do segmento coxa no tatame - Ss3.

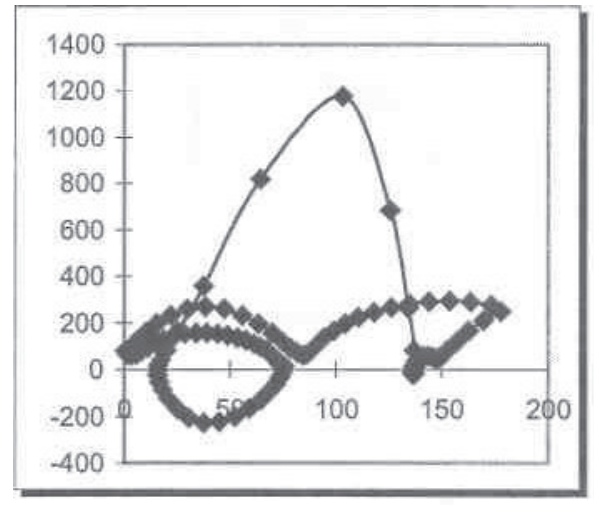

B) Retrato de fase do segmento perna no tatame - Ss3.

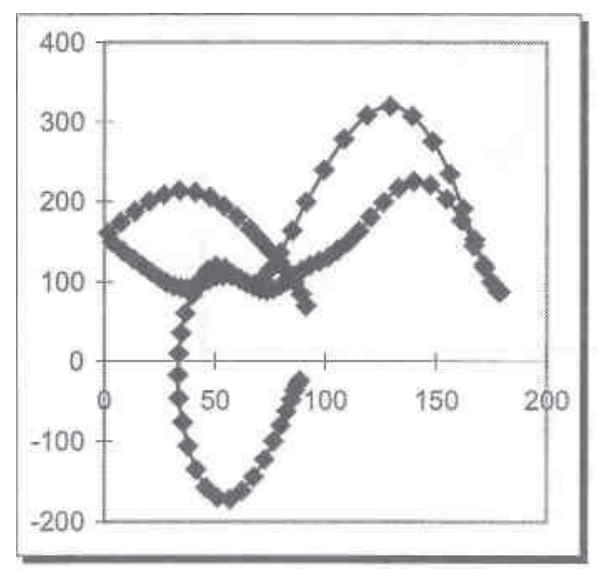

C) Retrato de fase do segmento tronco no tatame - Ss3

Figura 7. Órbitas atrativas dos segmentos da coxa (A), perna (B) e tronco (C), na execução do rolamento para frente sobre o colchão do sujeito 3 (Ss 3). 
co. Enquanto o ângulo da coxa aumenta em relação ao plano horizontal, os ângulos da perna e tronco vão diminuindo, ou seja, se movimentam em sentido inverso. A Figura 7 mostra o retrato de fase da perna e da coxa de uma mesma pessoa realizando o rolamento. Como podemos observar, as formas geométricas (retratos de fase) destes dois segmentos são muito diferentes.

Se partirmos do princípio que os segmentos da perna e coxa são modelados dinamicamente como ciclo-limite, então o comportamento dos dois segmentos juntos representam a acoplagem de dois ciclos-limites. Conforme CLARK, TRULLY e PHILLIPS (1993), um sistema dinâmico desta natureza tem previsões de comportamento específico que podem ser derivadas. Uma previsão segundo estas autoras é que osciladores de ciclolimite aos pares estarão encaixados (acoplados) um no outro. Acoplamento significa que dois : saladores operam não mais independentemente mas, em vez disso, de forma sincronizada, ou seja, um com o outro.

$\mathrm{Na}$ fase de preparação para impulsão, os deslocamentos angulares do tronco e da coxa são muito maiores do que os do segmento perna, e isto ocorre devido às alterações no centro de gravidade para mais próximo do solo, facilitando a impulsão dada pelos membros inferiores ao rolar para frente.

Para a maioria dos participantes, no início da mipulsão do rolamento para frente, o ângulo do segmento perna está próximo a $0^{\circ}$ e o da coxa em torno de $130^{\circ}$. A impulsão se dá de uma forma seqüencial, primeiro com uma reversão do segmento da coxa, ocorrendo quase simultaneamente reversão do tronco, devido à elevação do quadril. Por último, a perna atua de forma mopulsiva, impulsionando o corpo para o rolamento propriamente dito. Ao iniciar a reversão, tanto a perna como a coxa apresentam um aumento na velocidade angular.

Através dos gráficos dos retratos de fase da perna, coxa e tronco, pode-se notar que as mesmas
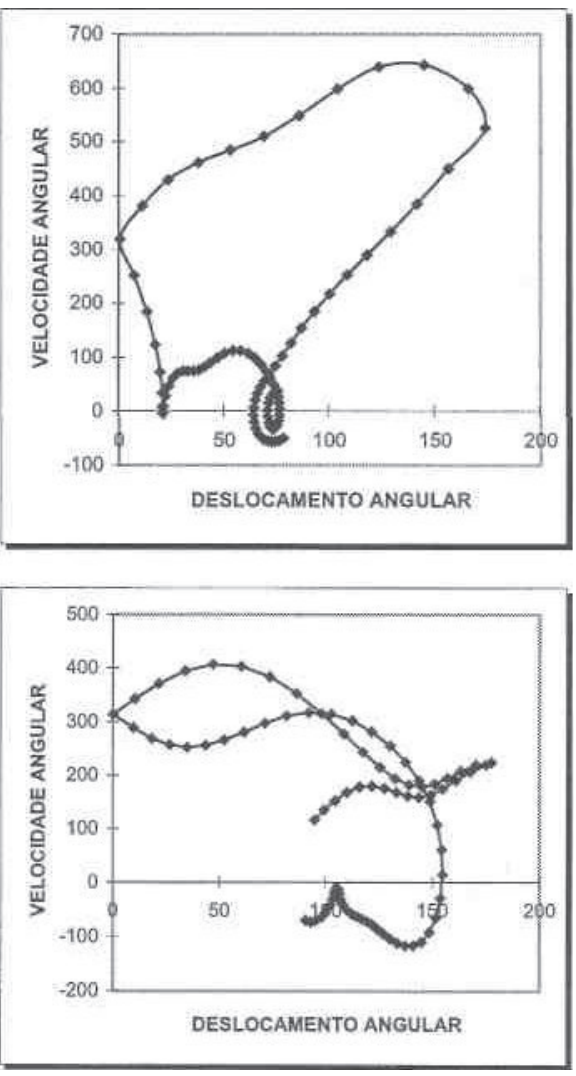

Figura 8. Retratos de fase da perna (A) e coxa (B) na realização do rolamento para frente sobre colchão (Ss 15).

características topológicas do rolamento para frente realizado no colchão foram observadas quando no tatame, com pequenas variações. Esta atração lhe dá robustez, oscilação persistente, mas os ciclos-limites podem perder sua estabilidade (CLARK, TRULLY \& PHILLIPS, 1993).

Cada segmento apresentou três reversões, comuns à performance de todos os sujeitos, em ambas superfícies (colchão e tatame), indicando que as diferenças de desenvolvimento observadas nos retratos de fase apresentados aqui são sutis. Isto pode ser visto quando comparamos o ciclo de uma criança do grupo de idade de 5-6 anos, com o ciclo de um adulto. Examinando as trajetórias da perna, algumas similaridades são evidentes. A maior diferença parece estar na amplitude da trajetória da criança que se mostra mais fechada. 
Já as trajetórias da coxa parecem diferir menos na forma, com direção e velocidade angular similares, atingindo uma velocidade máxima ao redor de 400 graus por segundo. Tanto o tronco como a perna apresentam diferença na abertura da trajetória. Enquanto as crianças possuem uma órbita mais fechada, o grupo de adultos mostra uma órbita mais aberta, sendo que a velocidade angular máxima, tanto para as crianças como para os adultos, gira em torno de 350 graus por segundo. Claramente, há diferenças ao longo das idades nas formas geométricas dos retratos de fases, mas argumentamos, com relação a estes resultados, principalmente quanto às diferenças nos parâmetros de controle que circundam a criança quando esta realiza o rolamento, não excedem uma magnitude crítica e portanto não criam novos padrões qualitativamente diferentes. Ao invés, estes parâmetros de controle afetam o tamanho total do ciclo-limite.

Os resultados das trajetórias dos segmentos perna, coxa e tronco mostraram ser diferentes, indicando que cada segmento apresenta um deslocamento espaço-temporal que lhe é próprio. Contudo, as trajetórias referentes a cada um dos segmentos, perna, coxa e tronco, foram semelhantes entre todos os sujeitos que participaram do estudo e nos dois pisos empregados. Embora existam pequenas diferenças nas trajetórias dos segmentos perna, coxa e tronco entre os sujeitos, uma menor variabilidade foi detectada no grupo de adultos, sendo que estes apresentaram um padrão mais consistente.

Os retratos de fases mostram portanto um padrão dinâmico específico e reconhecível para a perna, coxa e tronco, independente da idade. No grupo de adultos isto fica mais evidente, demostrando uma ótima interação do organismo com o ambiente durante a ação.

\section{Conclusões}

O objetivo do presente estudo foi investigar o rolamento para frente sob as influências das restrições internas e externas, ou seja, verificar a organização espaço-temporal do rolamento para frente, diante de restrições internas e externas. Apoiado no resultado da análise apresentada podemos concluir que:

- o rolamento para frente apresenta retratos de fase para os segmentos da perna, coxa e tronco, com características topológicas específicas, portanto não ocorrem mudanças na organização espaço-temporal dos segmentos da perna, coxa e tronco em diferentes faixas etárias, frente às variações das restrições internas;

- ao longo do desenvolvimento, os sujeitos de todos os grupos etários apresentam uma mesma configuração dinâmica, com pequenas variações entre os participantes;

- as mesmas características topológicas para os segmentos foram observadas nos dois pisos, indicando que a mudança nas superfícies de ação, não foram suficientes para causar uma organização espaço-temporal diferente, pois não ocorrem mudanças na organização espaço-temporal dos segmentos da perna, coxa e tronco frente às restrições externas em que foram realizados os rolamentos.

Este trabalho teve caráter descritivo-experimental exploratório e nenhum outro estudo sobre o rolamento para frente utilizando este tipo de abordagem experimental foi encontrado. Este fato restringiu a discussão dos resultados obtidos. Consideramos ainda que outras pesquisas se fazem necessárias com diferentes métodos de análise para melhor compreensão da coordenação e do controle do desenvolvimento desta habilidade. 


\section{Referências Bibliográficas}

BARELA, J.A. Desenvolvimento do saltar à horizontal: uma análise topológica. Porto Alegre, p.100. Dissertação (Mestrado em Ciências do Movimento Humano) Escola Superior de Educação Física, UFRGS, 1992.

CATUZZO, M.T. Os padrões de coordenação na seqüencia de desenvolvimento do saltar à horizontal: uma visão dinâmica. Porto Alegre. p.l 14. Dissertação (Mestrado em Ciências do Movimento Humano) Escola Superior de Educação Física, UFRGS, 1994.

CLARK, J.E., PHILLIPS, S.J. The development of intralimb coordination in the first six months of walking. In: FAGARDJ., WOLFF (Eds.). Dynamical systems in development: 1 application. Cambridge, MA: MIT, 1991.

CLARK, J.E., TRULLY, T.L., PHILLIPS, S.J. On the development of walking as a limit-cicle system. In: SMITH, L.B, THELEN, E. (Eds.) A dynamic approach to development. England: A Bradford Book. p.71-93, 1993.

CLARK, J.E., WHITALL, J. What is motor development? The lessons of history. Quest, v.41 p.183-202, 1989.

GALLAHUE, D.L. Understanding motor development in children. New York: John Wiley \& Sons, 1982.

GODFREY, B.B., KEPHART, N.C. Movement patterns and motor education. New York: Appleton-Century-Crofts, 1969.

HAYWOOD, K.M. Life span motor development. Champaign, IL: Human Kinetics, 1986.

KELSO, JAS., DING, M. Fluctuations, intermittency, and controllable chaos in biológica! coordination. In: NEWELL,K.M, CORCOS.D.M. (Eds.). Variability and motor control. Champaign, II: Human Kinetics. p.291-316,1993.

KELSO, J.A.S., DING, M., SCHÓNER, G. Dynamic pattern formation: a primer. In: SMITH.L.B,THELEN,E. (Eds.). A dynammic systems approach to development: applications. p.13-50, 1993.

NEWELL, KM. Coordination, control and skill. In: GOODMAN, D., WILBERG, R.B., FRANKS, LM. (Eds.). Differing perspectives in motor learning, memory and control. Amsterdam: NorthHolland. p.295-315, 1985.

PELLEGRINI, A.M. Tendências no estudo do desenvolvimento motor. In: BENTO, J., MARQUES, A. (Eds). As ciências do desporto e a prática desportiva/desporto na escola desporto de reeducação e reabilitação-actas. Universidade do Porto, Faculdade de Ciências do Desporto e de Educação Física, v.1, p.379-91, 1991.

THELEN, E., SMITH, L.B. A dynamic systems approach to the development of cognition and action. Cambridge, MA.: MIT Press, 1994.

THELEN, E., ULRICH, B.D. Hidden skills: a dynamic systems analysis of treadmill stepping during the first year. Monographs of the society for research in child development. Serial 223 (56), 1991.

TURVEY, M.T, FITCH, H.L., TULLER, B.. The Berstein perspective: I the problem of degrees of freedom and context-conditioned variability. In: KELSO,JA.S. (Ed.). Human motor behavior: an introduction. Hillsdale, New Jersey: LEA. p.239-52, 1982.

WICKSTROM, R.L.. Fundamental motor patterns. 3 ed. Philadelphia: Lea \& Febiger, 1983.

\section{Notas}

* Prof. da E.E.P.S.G. Prof. Gabriel Pozzi, LimeiraSP e Prof. da disciplina Educação Física Adaptada do Curso de Educação Física da Faculdade de Filosofia, Ciências e Letras de São José do Rio Pardo, SP. Mestre em Ciências da Motricidade pela UNESP, Rio Claro. 
**Prof $f^{a}$ Titular de Aprendizagem e Controle Motor do Departamento de Educação FísicaUNESP, Rio Claro. Mestre e Doutora pela Universidade de Illinois, Urbana-Champaign, EUA, e Livre-docente pela UNESP, Rio Claro.

Alaercio Perotti Jr

R. Alan Kardec - 66 V. Piza - Limeira - SP

CEP 13.480-162 -Tel. (019) 3442-3254

Ana Maria Pellegrini

Av. Brasil - 1431 - Rio Claro - SP

CEP 13.505-600-Tel. (019) 535-3198

Obs: Trabalho elaborado com base na Dissertação de Mestrado do primeiro autor no Curso de Pós-Graduação em Ciências da Motricidade, UNESP, Rio Claro. 